\title{
DEBUNKING DOXASTIC TRANSPARENCY
}

\author{
Ema Sullivan-Bissett ${ }^{1}$ \\ ${ }^{1}$ University of Birmingham \\ Original scientific article - Received: 28/11/2022 Accepted: 9/2/2022
}

\section{ABSTRACT}

In this paper I consider the project of offering an evolutionary debunking explanation for transparency in doxastic deliberation. I examine Nicole Dular and Nikki Fortier's (2021) attempt at such a project. I suggest that their account faces a dilemma. On the one horn, their explanation of transparency involves casting our mechanisms for belief formation as solely concerned with truth. I argue that this is explanatorily inadequate when we take a wider view of our beliefformation practices. I show that Dular and Fortier overstate the extent to which adaptive non-evidentially supported beliefs are rare, and the implausibility of disjunctive evolutionary systems. They should allow a role for the non-truth directed behaviour of our mechanisms of beliefformation. On the other hand, we might restrict the explanation offered by Dular and Fortier to the deliberative context, that is, we might understand them as allowing for non-evidential belief formation outside of the deliberative context, but as identifying the key to explaining transparency in the truth-directed evolutionary mechanisms as they operate in the deliberative context. However, this would land them on the second horn of the dilemma: we would then have no different an explanation to one I have offered elsewhere (2018), an explanation which Dular and Fortier explicitly put aside as engaged in a project different from their own. I finish by briefly considering some broader implications relating to explaining transparency, the nature of belief, and the prospects for pragmatism. I conclude that Dular and Fortier's debunking explanation of transparency bestows an implausible role for truth in fixing our beliefs, or, if it doesn't, then we simply have the restatement of a view explicitly disavowed by the authors. We are left, then, with an explanation we ought not want, or an explanation we already had.

Keywords: belief; transparency; doxastic deliberation; evolutionary debunking; reasons for belief. 


\section{Transparency}

Transparency characterizes deliberation over belief: "when asking oneself whether to believe that $p$ " one must "immediately recognize that this question is settled by, and only by, answering the question whether $p$ is true" (Shah 2003, 447). The structure of doxastic deliberation is such that non-truth related considerations cannot play a conscious role in our coming to a belief: the question whether to believe that $p$ collapses into the question whether $p$ is true.

It is important to note that the move from the question whether to believe that $p$ to the question whether $p$ is true is "immediate and not inferential" (Engel 2007, 198). There is no bridging step in doxastic deliberation moving one from the truth of $p$ to belief that $p$. Rather, answering the question whether $p$ just is to answer the question whether to believe that $p$. It is also worth noting that to accept that transparency characterizes doxastic deliberation is not to over-intellectualize that process, that is, for a subject's deliberation to exhibit transparency, she need not explicitly pose herself the question whether to believe that $p$. Rather, it is enough that her thinking "manifests some recognition that this is the question" in play (Shah 2003, 466).

Dular and Fortier offer an evolutionary debunking explanation of why transparency characterizes our doxastic deliberation. In what follows I will not argue that transparency characterizes our doxastic deliberation, but will assume that it does, and focus on how it might be explained. ${ }^{1}$

\section{Extant Explanations}

Two broad kinds of explanation have been offered of transparency in doxastic deliberation, these explanations work from the agential level; with the believer playing a role in the structure of doxastic deliberation, where that role falls out of the essential nature of belief.

Teleological accounts of belief explain transparency by appeal to the aim a believer adopts in posing the deliberative question. Since, according to this view, belief essentially aims at truth, when in the business of deliberating over whether to believe that $p$, truth considerations are the only ones of relevance, since they are the only ones conducive to achieving belief's aim. I have argued elsewhere that such an explanation places the

\footnotetext{
${ }^{1}$ For dissent see Conor McHugh (2012, 2013; cf. Archer 2017; Sullivan-Bissett 2017a), and Miriam McCormick (2015; cf. Sullivan-Bissett 2017b).
} 
teleologist on the horns of a dilemma. ${ }^{2}$ On the one hand, the so-called aim of belief is not appropriately characterized as an aim, since it does not behave in an aim-like way (it cannot be weighed against a believer's other aims (Owens 2003)). ${ }^{3}$ On the other hand, if the aim could be weighed (such that my aim to believe truly could be weighed against my aim to form beliefs that will make me happy), it should not be the case that transparency characterizes our deliberation. If belief were governed by an aim, the question whether to believe that $p$ would not collapse into the question whether $p$ is true. So even if there were a weighable aim of truth essential to belief, it wouldn't be at the required strength to explain transparency (Sullivan-Bissett 2018, 3457-3460).

An alternative approach comes from normative accounts of belief, which have it that belief aims at truth only metaphorically. Instead of taking the idea of an aim of belief literally, normativists claim that belief is constitutively norm-governed. Many formulations of an explanatory norm for belief have been offered, but there is some agreement that it must be formulated in terms of one being permitted to believe that $p$ when $p$ is true ('ought' formulations would be too demanding (see Bykvist and Hattiangadi 2007)).

With a permissibility norm in place, one normative explanation for transparency has gone like this: when an agent deliberates on the question whether to believe that $p$, that deliberation is framed by the prescription to believe that $p$ only if $p$ is true. In doxastic deliberation, an agent expresses her commitment to this prescription, which activates two dispositions: one to be moved by considerations relevant to the truth of $p$, and one which blocks considerations which are irrelevant to the truth of $p$ (Shah 2003, 467; Shah and Velleman 2005, 519).

However, as I have argued elsewhere, this explanation does not work. It being permissible to believe that $p$ is a very different thing from it being settled for you to believe that $p$. If it were a permissibility norm which explained the structure of deliberation, it ought to be possible to nevertheless not believe that $p$ upon ascertaining that $p$ is true, after all, one is merely permitted and not obligated to believe it. But this non-adherence to the putative norm is not possible, and so the putative norm is not strong

\footnotetext{
${ }^{2}$ Not to be confused with Nishi Shah's (2003, 460-465) Teleologist's Dilemma. He argues that a descriptive account of the nature of belief (as being regulated for truth via some aim) will either be too strong to accommodate non-deliberative belief, or too weak to explain transparency. For more on this, see Asbjørn Steglich-Petersen (2006, 2017a) and Sullivan-Bissett and Lisa Bortolotti (2017).

${ }^{3}$ For discussion on whether the teleological account does indeed face this horn of the dilemma see the back and forth between Steglich-Petersen, and Sullivan-Bissett and Noordhof (Steglich-Petersen 2009; Sullivan-Bissett and Noordhof 2013; Steglich-Petersen 2017b; and Sullivan-Bissett and Noordhof 2017).
} 
enough to generate transparency, and cannot explain it (see SullivanBissett 2018, 3461-3462 and Sullivan-Bissett and Noordhof 2020).

As noted earlier, these accounts proceed by taking transparency to be a result of something the agent does, in virtue of some specified essential nature of belief (it being truth-aimed or norm-governed). In this way, they take the essential nature of belief to be relevant to the project of explaining transparency. This is problematic because in both cases, if the relevant aim or norm were doing the work of explaining transparency, there ought to be significantly more wiggle room upon discerning that $p$ than there in fact is. ${ }^{4}$ Let us turn then to Dular and Fortier's explanation, on which the believer is a much more passive player in the structure of doxastic deliberation.

\section{Dular and Fortier's Evolutionary Debunking Explanation}

Dular and Fortier aim to level the playing field between evidentialists (who have it that only reasons relating to evidence can be reasons to believe) and pragmatists (who have it that there can be reasons to believe not related to evidence). In particular, they aim to show that transparency does not help us adjudicate between these positions. To do so, they seek to provide an explanation of transparency consistent with pragmatism. At first blush, if we want transparency to be explainable by, or even consistent with, our account of epistemic reasons, evidentialism has a much easier time of it. For an evidentialist, reasons for believing that $p$ are restricted to considerations relating to evidence supporting the truth of $p$, there are no non-evidential related reasons for belief. A natural thought then is that transparency characterizing our doxastic deliberation is simply evidentialism in action. Since evidential reasons are the only kind of reasons we can have for belief, of course only such reasons enter into deliberation over whether to believe a given proposition. There is no presence of pragmatic considerations in deliberation of this kind since no such considerations could represent reasons for belief. Of course, transparency ought not be understood as the claim that one "cannot so much as be struck by pragmatic considerations" (McHugh 2013, 449), the point is rather about which considerations can be motivationally efficacious. Evidentialism seems nicely aligned with doxastic deliberation so characterized, and might even find support in it (see e.g. Shah 2006).

\footnotetext{
${ }^{4}$ Not all explanations of transparency which draw on the essential nature of belief will be problematic in this way. For example, Kate Nolfi's (2015) action-oriented functional account of belief might naturally explain transparency by appeal to the essential functional role belief plays in a believer's mental economy. (To my knowledge Nolfi hasn't explicitly put her account to such work, but an explanation along these lines might not face the problems of the teleological and normative accounts.)
} 
Again, at first blush, pragmatism looks to be in trouble. If there are ever non-evidential reasons for belief, why can we not take those into consideration when deliberating over whether to believe that $p$ ? It is not merely that they do not arise for us, rather, we can ostensibly recognize pragmatic considerations for believing (or not), but such considerations lack any motivational force when it comes to settling one way or another, they do not rise to the level of reasons. The pragmatist then owes us an explanation of why, from the first-person point of view, only one kind of reason (the evidential kind) gets to determine the outputs of doxastic deliberation.

Dular and Fortier's approach is to understand transparency as the result of evolutionary selection that, in its crudity, could not set us up more precisely in a way which reflected the truth about the nature of reasons to believe. Evolution has set us up to respond only to the class of reasons which more reliably produce adaptive beliefs (i.e. those that increase our inclusive fitness). That class is the one related to evidence, for obvious reasons. As W. V. O. Quine pointed out, "creatures inveterately wrong in their inductions have a pathetic but praiseworthy tendency to die before reproducing their kind" (Quine 1985, 39). So, Dular and Fortier argue, transparency results from our mechanisms of belief production being selected for being geared towards truth, such that non-evidential considerations cannot enter our deliberation as reasons to believe. Here is their explanation in full:

In almost every case, only taking evidential considerations into account will be more fitness-conducive than if we instead formed beliefs according to how well they would advance our ends. For instance, if I am deliberating about whether to believe that there is a tiger over the hill, and the evidence available to me suggests that there is in fact a tiger over the hill, then it is hard to see how deliberating in a way that takes my ends into account (rather than strictly truth) would be more evolutionarily advantageous than simply deliberating in a way that respects the evidence. [...] since beliefs based on evidentialist considerations are more likely to result in true beliefs than beliefs that are based on pragmatist ones, the pragmatist has an explanation for why people in fact collapse the question of whether to believe that $p$ into the question whether $p$. It is not that, by doing so, they are incredibly adept at picking up on epistemic norms; rather, it's that evolution has selected for the cognitive system that would best promote our survival, and this cognitive system is one that is responsive to truth. (Dular and Fortier 2021, 1461-1462) 
This is consistent with pragmatism understood as an account of how we should form beliefs since the explanation of transparency is concerned with the descriptive question of how we in fact do. Pragmatists then, unlike evidentialists, simply fail to find their account of reasons to believe reflected in the structure of doxastic deliberation. But that's a matter of contingency-evolution went with the route which would more often produce adaptive beliefs. True beliefs are usually the adaptive ones. The cost is our not being able to consciously respond to pragmatic reasons for belief, but that is not to say that there are no such reasons.

It might be thought that the kind of explanation on offer here misses something crucial about the explanatory project, namely, that the phenomenon to be explained is necessary to belief, and not some evolutionary contingency. I have argued elsewhere that the claim that transparency is a necessary phenomenon of belief is ill-motivated, and so explanations which do not honour necessity are not vulnerable to objection based on not so honouring (Sullivan-Bissett 2018, 3471-3472). Suffice to say for the sake of this paper that I am not in the business of objecting to the contingent nature of transparency. In discussing explanations which have contingency as an outcome, my argument is downstream of any debate concerning the reasonableness of weakening the metaphysical strength of transparency.

In the next two sections I argue that Dular and Fortier's approach finds itself on the horns of a dilemma. On the one horn, their evolutionary account of the relationship between belief and truth fails to properly accommodate the range of beliefs formed on non-evidential grounds ( 44$)$. One way to avoid this charge is to restrict the account to the context of doxastic deliberation. However, this places their account on the second horn - it is no different from an account put forward elsewhere which they explicitly distance themselves from as one engaged in a different explanatory project $(\$ 5)$. More broadly, a wider view of the nature of belief is needed to contextualise the explanation of transparency, and the details of this wider view will be relevant to whether evidentialism and pragmatism are in fact on a theoretical par $(\S 6)$.

\section{Horn One: Non-truth Directed Beliefs}

Dular and Fortier often talk about our "cognitive system" responsible for beliefs as a whole. For example, they say "evolution has selected for the cognitive system that would best promote our survival, and this cognitive system is one that is responsive to truth" $(2021,1462)$, and that "we still ought to think that natural selection favors systems that generate true 
beliefs" (2021, 1463). However, the claim that there's a single aim for mechanisms of belief formation (truth) leaves no room for the idea that in certain contexts, these mechanisms are not truth-aimed, but are nevertheless doing what they ought to be doing. In some cases, the beliefs it is adaptive to have are not aimed at truth. Dular and Fortier seem to disagree, they say, "notice how rare cases are where having a nonevidentially supported belief would be better for survival" $(2021,1461)$. I think they underestimate how many human beliefs are adaptive in spite of their not being aimed at truth.

There are many cases of false belief which seem to have been produced by mechanisms doing what they are supposed to do. That is, producing beliefs that are adaptive, but not in virtue of being true. Such cases reveal that our mechanisms for belief formation are not solely concerned with truth. Let us consider some examples.

We can think first in terms of biases, and distinguish hot biases (those driven by emotions and desires) and cold biases (those which are nonmotivational and emerge from heuristics). ${ }^{5}$ Cold biases include the availability heuristic (our tendency to rely on examples which easily come to mind as representative) and the confirmation bias (our tendency to search for or interpret information that confirms our existing beliefs) (for more see Mele 1997, 93-94). Such biases may be present in our cognitive systems because they tend to guide us towards truth, and so we may find no reason from these quarters to think our beliefs are aimed at anything but truth. Hot biases however are a different matter; these are biases arising from our desiring that $p$ or desiring to believe that $p$. Examples include selective attention to evidence, and selective evidence gathering (for more see Mele 1997, 94-5, 2006, 110). It is biases such as these that might play a role in the belief-formation processes resulting in false beliefs which are nevertheless useful, for example, self-deceptive beliefs. ${ }^{6}$

It could be said in response to the foregoing that cases of useful false beliefs are not plausible candidates for adaptive beliefs produced by mechanisms doing what they are supposed to do, but are rather examples of our mechanisms for belief production going awry (and getting lucky in producing helpful beliefs). But there are good reasons to think this is not the case. For example, unrealistic beliefs about oneself lead to engagement

\footnotetext{
${ }^{5}$ This distinction has been traced back to R. P Abelson (1963) (see Elster 1983, 141).

${ }^{6}$ They may do so in at least two broad kinds of way. On an anti-intentionalist story, the hot biases influencing the formation of the self-deceptive belief are not intentional (see e.g. Mele 1997, 2006). More controversially perhaps, on an intentionalist story, a subject may intentionally bias her cognitive processes so as to favour a belief that $p$ (see Talbott 1995). I favour an anti-intentionalist account, and some of what I say in what follows may more naturally fit such a framework.
} 
in adaptive behaviours (Taylor and Brown 1994), and "optimal mental health is associated with unrealistically positive self-appraisals and beliefs" (see McKay and Dennett 2009, 505-508 for discussion). As Nolfi has pointed out in her discussion of the optimism bias, research

supplies compelling evidence that we are, as a general rule, more successful in achieving our various ends when our beliefs about ourselves and about our relationship to the world around us are systematically distorted in particular ways. (Nolfi 2018, 192)

Self-deceptive beliefs may also be adaptive by (1) helping us to be better deceivers, (2) preventing parent-offspring conflict to maintain parental investment, or (3) for the same reasons as biases towards optimism, i.e. the various benefits of a positive stance (Trivers 2000, 2011, 2013, cf. Van Leeuwen 2007a). Other examples might include our moral beliefs, which are adaptive insofar as they facilitate cooperation and social cohesion (Ruse 1986; Joyce 2001; cf. Enoch 2011; Fitzpatrick 2014), and beliefs about epistemic normativity which are adaptive insofar as they make us better at responding to epistemic considerations (Street 2009; SullivanBissett 2017c, 2020). Slightly less plausible perhaps are clinical delusions, ${ }^{7}$ which might be adaptive insofar as they help to deceive others into social alliances (Hagen 2008; cf. Gold and Gold 2014), or insofar as they maintain behavioural interactions in the face of abnormal prediction-error signaling ${ }^{8}$ (Fineberg and Corlett 2016; Mishara and Corlett 2009; cf. Lancellotta 2021). All of these cases are ones where the cognitive mechanisms responsible are not responding to truth, but are nonetheless producing adaptive beliefs. ${ }^{9}$ Perhaps there are more besides (candidates might include beliefs arising from conspiratorial ideation or confabulation). It would be surprising if all of these cases were ones where things had gone wrong, especially given how widespread some of them

\footnotetext{
${ }^{7}$ Of course, any serious defence of the adaptiveness of delusions will need to attend to heterogeneity in this category (see Bortolotti 2009, 23-27 for an overview; see also Lancellotta and Bortolotti for discussion of adaptiveness informed by McKay and Dennett's 2009 shear pin hypothesis). Since I am not defending any of these views but referring to them only to illustrate the range of candidate adaptive beliefs, I won't discuss this further.

${ }^{8}$ Prediction-error theories have it that perceptual processing involves the generation of predictions about sensory input, from antecedently held perceptual hypotheses about the world, with the aim of updating the hypotheses to minimize the error of these predictions on the basis of comparison between the predictions and sensory input. Delusions are said to derive from the malfunctioning of this process, for example, faulty signals that a prediction isn't met leading to erroneous updating.

${ }^{9}$ I have been speaking as though these beliefs arise from the same mechanisms as those beliefs which seem to respond to evidence, or which are seeking to track truth. Of course, something rather different might be going on. It might be that the mechanisms producing adaptive beliefs (but not in virtue of their aiming at truth) are different from the mechanisms producing beliefs aimed at truth. If that were right, we would nevertheless have cases where the existence of false beliefs would be in virtue of design, not mistake.
} 
are, and how they contribute positively to inclusive fitness. The existence of these beliefs looks, then, to be in virtue of design not mistake. ${ }^{10} \mathrm{Of}$ course, given that deliberative belief formation is characterized by transparency, our mechanisms of belief formation must be operating below the level of consciousness when they aim at something other than truth (cf. Talbott 1995). But their doing so gives us sufficient reason to be sceptical that such mechanisms are, in general, solely geared towards truth.

Dular and Fortier consider a nearby objection to their view which has it that evolution would in fact favour a cognitive system that had us believe in accordance with the evidence unless it would be more conducive to survival not to. They call this a "disjunctive" system. In response, they say that "this proposed system is simply too complex for evolution to have selected" (Dular and Fortier 2021, 1464). They go on:

[I]t seems as though if evolution had favored the disjunctive system, we would also need another system that would help us determine when to believe in accordance with evidential considerations, and when to believe in accordance with nonevidential considerations. Given the rarity of cases in which non-evidential reasons for belief do a better job at promoting survival than evidential reasons for belief, coupled with the fact that the disjunctive system is so complex, we have good reason to think that natural selection would have favored the psychologies that we in fact have, rather than ones that employ the disjunctive system. (Dular and Fortier 2021, 1464)

Let us understand a disjunctive evolutionary system as one which performs multiple functions, depending on the circumstances of the organism. A single belief system which produced beliefs aimed at the truth in some circumstances, and produced beliefs aimed at usefulness unconnected to truth in others, would count as a disjunctive system in this sense. Dular and

\footnotetext{
${ }^{10}$ Of course, none of these views are without their critics (as indicated in the citations), but the sheer number of evolutionary adaptation accounts of various kinds of belief exert enough pressure on Dular and Fortier's claim that non-evidentially formed beliefs promoting survival represent a rarity (Dular and Fortier 2021, 1461). Indeed, as William J. Talbott notes, although knowing the truth can enhance our ability to fulfil our desires, there are many cases where it does not, and indeed may produce highly undesirable psychological effects, and so many adaptive beliefs are ones arising out of hot cognition (1995, 27-28). Another way of resisting the force of these putative examples of false but adaptive beliefs is to endorse non-doxasticism about them. If these attitudes are not beliefs, then they were not produced by mechanisms of belief production, and cannot be harnessed in any argument about the nature of those mechanisms. Dular and Fortier may well take this line, although it is unclear to me what the principled grounds would be, and usual ones which motivate non-doxasticism to do with relationships to evidence may not be natural ones for pragmatists to take. In any case, although far from settled, I refer readers to defences of doxasticism elsewhere (for delusion, see Bortolotti 2009 and Bayne and Pacherie 2005; for self-deception, see Van Leeuwen 2007b).
} 
Fortier have it that the rarity of cases of false but useful beliefs gives us reason to think there is no such system operative in our mechanisms of belief formation.

However, if I am right that at least some of the beliefs surveyed above are examples of false but adaptive beliefs produced by design and not mistake, that right there is our evidence that a disjunctive system is not so complex after all. So how would it work? We might say something like this: at the coarsest level of description, our mechanisms for belief production have the function of producing adaptive beliefs. But they do that in one of two ways: by producing beliefs aimed at truth, or by producing beliefs which facilitate some other good but not as an approximation to truth. These two ways of producing adaptive beliefs might map onto two sets of historically appropriate conditions for the performance of the two respective functions. The historically appropriate conditions for the production of true beliefs plausibly diverge from the conditions appropriate for the production of beliefs not aimed at truth.

Take self-deception for example. In the case of wishful self-deception the subject desires that $p$, has ample evidence that not- $p$, and goes on to believe that $p$. Such cases are ones where believing that not- $p$ might be psychologically damaging, and believing that $p$ would prevent that damage and perhaps bring some additional psychological benefits. Plausibly a motivational condition is met in such situations, whereby mechanisms of belief production are thus geared not towards truth, but towards the effective functioning of the subject (see also Noordhof 2003 for related cases that don't involve self-deception). What is so implausible about this?

Dular and Fortier ask us to believe in a system geared solely towards truth because adaptive non-truth directed beliefs are rare, and a system which tracked truth sometimes and at other times did not would be too complicated to be favoured by evolution. We have seen though that there is a large swathe of candidates for false but adaptive beliefs, and, given that, we have reason to think that a disjunctive system is both possible and actual. This is an important point because Dular and Fortier ward off an objection to their view by appeal to the unlikelihood of disjunctive evolutionary systems. If such systems are not unlikely after all, Dular and Fortier owe an explanation of why pragmatism about reasons to believe is not better reflected in our practices of belief formation. 


\section{Horn Two: Restricting to the Deliberative Context}

In reply to the foregoing Dular and Fortier may restrict their view to the context of deliberation where any non-evidential considerations cannot be consciously considered. That would leave it open that in the nondeliberative context, our mechanisms of belief formation could produce adaptive beliefs, but not by aiming at truth. This looks like a move they make in a footnote when they say:

[O]ne might think that evolutionary pressures make us messy, such that sometimes we would form beliefs based on pragmatic considerations instead of, as we've claimed here, never doing so (given the truth of transparency). However, notice that transparency is a claim about explicit doxastic deliberation, and so our evolutionary explanation only concerns this context. Notice that this is compatible with people sometimes forming beliefs based on pragmatic considerations outside of the context of explicit doxastic deliberation. (Dular and Fortier 2021, 1464, fn. 38)

Here, Dular and Fortier seem not to be against our mechanisms for belief formation being a bit more pragmatic in some contexts, perhaps consistent with some of the ways suggested in the previous section. But in the absence of a disjunctive deliberation whereby we could appropriately regulate our responses to evidential and pragmatic considerations, from the first-person perspective, evolution had a choice: have us respond to only evidential considerations in deliberation, or only pragmatic ones. I think that Dular and Fortier are quite right when they say:

[I]t is implausible that including non-evidential reasons in our doxastic deliberations would generally promote our survival better than only the evidentialist reasons, and, as it's widely known, evolution selects for general systems rather than more fine-grained ones. (Dular and Fortier 2021, 1462)

However, if the claim is that evolution selected for doxastic deliberation being restricted to epistemic considerations, and that's consistent with there being other mechanisms in play in other contexts where pragmatic considerations are involved, then the explanation here is no more than what is present elsewhere (notably Sullivan-Bissett 2018). Now of course, philosophers can happen upon the same view independently in ignorance of one another, such occurrences represent no good grounds for objection. However, this is not such a case. Dular and Fortier mention my argument in an aside, saying that 
[t]hough addressing the question of what distinguishes belief as a unique mental state, and not the topic of epistemic reasons, Sullivan-Bissett (2018) also gives an evolutionary explanation of transparency to defend her motivational account of the nature of belief. (Dular and Forter 2021, 1461, fn. 22)

It is on these grounds that they put the account aside.

But the account cannot so easily be put aside if Dular and Fortier are badging themselves as providing an evolutionary debunking account of transparency which does not generalize to belief formation in general, that is, an explanation which doesn't rule out non-evidential influences on belief outside of the deliberative context. And that is because I do exactly the same thing. It is false that my account of transparency is one put forward in the spirit of defending a motivational account of belief's nature, and so it cannot be put aside on the grounds that it is engaging in some different explanatory project. I adopt a motivational account of the essential nature of belief, taking up the characterization of the role suggested (but not endorsed) by Lucy O'Brien: all that is necessary for a state to be a belief is that it

by itself, and relative to a fixed background of desires, disposes the subject to behave in ways that would promote the satisfaction of his desires if its content were true. (O'Brien 2005, 56)

This constitutive feature of belief simply sits in the background of my account of transparency. The work done by the adoption of the motivational view is that of picking out the essential nature of belief across worlds in a way which does not appeal to the connection between belief and truth. As we saw earlier, other explanations have taken transparency to fall out of what is essential to belief (its truth aim or norm). My approach is to divorce the essential nature of belief from truth, and to move away from seeing transparency as a consequence of the nature of belief. Instead, I ground the explanation of transparency in the particular (biological) circumstances of human belief formation. With respect to the motivational account being able to explain transparency, I am very clear that it cannot:

[T] he account under consideration gives us a gap between whether $p$ is true and whether to believe that $p$. But there is no such gap in doxastic deliberation, truth is not an optional end. A motivational account of belief does not have the resources to explain why this is the case. (Sullivan-Bissett 2018, 3465) 
It is false, then, that my explanation of transparency is offered in the service of defending the motivational role component of my overall view. So what can explain transparency then? I explained it like this:

Given that our mechanisms for belief-production have the relational proper function of producing devices with true contents, the story for their selection includes their Normally producing true beliefs. In the deliberative case our cognitive architecture is arranged such that when we deliberate as to whether to believe that $p$, we, at the agent-level, are only sensitive to the adaptor (our environment) because this makes the adapted device (the resulting belief) more likely to perform its derived proper function of being true. The neurological structures which secure transparency have been selected for their role in producing true beliefs. (Sullivan-Bissett 2018, 3470)

Now, notwithstanding some of the terms used to pick out what is going on, this strikes me as indistinguishable from the explanation offered by Dular and Fortier. Both explanations identify transparency as an evolutionary adaptation designed to guide our doxastic deliberation towards evidential considerations in the pursuit of true beliefs. Both explanations take beliefs guided as such to be more evolutionarily advantageous than beliefs which could be formed, deliberatively, on the basis of non-evidential reasons. So in their casting transparency as a product of evolution gearing our doxastic deliberation towards truth, Dolar and Fortier offer no more than is offered in the above explanation. Making it explicit that such an explanation is consistent with pragmatism is a point worth noting, but that ought not be confused with having offered "an alternative explanation of transparency" (Dular and Fortier 2021, 1457) as advertised. The point isn't merely that Dular and Fortier have offered an identical explanation as offered elsewhere, it is that their having done so is based in part on a misinterpretation of an account which is, in fact, identical to their own.

\section{Broader Considerations}

I want to close with some broader considerations on the nature of belief, transparency, and the prospects for pragmatism. On the face of it, transparency may seem to tell us something about the nature of belief (that it is constitutively linked to truth) and about the nature of reasons for belief (that they are linked to truth, or evidence suggestive of it). On its face, transparency thus looks friendly to fans of a constitutive belief-truth link, and fans of evidentialism. 
We have seen that my approach is one that denies the constitutive link claim, while Dular and Fortier are interested in denying the exclusivity of evidential reasons claim. We have also seen that the strategy for doing so is - contra Dular and Fortier - exactly the same. The explanation given of transparency is one which has it as a phenomenon arising out of evolutionarily selected mechanisms of belief formation. For me, the lesson is that transparency does not follow as a result of something the believer does, given the essentially truth-related nature of belief, but is rather something to which the believer passively responds. For Dular and Fortier, explaining transparency as the consequence of evolutionarily selected mechanisms of belief formation allows them to divorce the nature of reasons to believe from the reasons evolution has set us up to recognize as reasons to believe in the deliberative context. However, as I have argued, this point need not rely on the claim that disjunctive evolutionary systems are implausible. Indeed, I take it that my account of transparency is perfectly friendly to pragmatism in precisely the way that Dular and Fortier take their account to be (even if, as it happens, I favour an error theoretic approach to reasons for belief, see my 2017c and 2020). It should thus be clear that the evolutionary debunking explanation of transparency is consistent with pragmatism, without entailing it.

Indeed, whether an explanation of transparency is consistent with a particular view of the nature of epistemic reasons will depend on broader considerations. That is, it will depend on the background notion of belief in operation. For the evidentialist this hardly needs stating: they will typically allow their preferred theory of epistemic reasons to carry the explanatory burden of transparency, set nicely against a background of belief as essentially connected to truth, either through a constitutive aim or norm. For the pragmatist, things are not as straightforward, since their preferred theory of reasons for belief does not so easily lend itself to an explanation of transparency (that explanation has to be located elsewhere). My conception of belief is ontically thin - it's simply an attitude which plays a given motivational role, all else equal. Given its thinness, the essential nature of belief is not apt to generate norms of good belief regulation, and so is silent on the debate between evidentialists and pragmatists. However, not all accounts of belief which de-prioritize truth and evidence will have this result.

Nolfi's work demonstrates this point. In particular, her approach teaches us that the rejection of a constitutive role for truth in belief does not amount to an endorsement of pragmatism, nor does it amount to a rejection of the idea that belief is constitutively normative. Rather, Nolfi's proper function account of belief has it that the relevant constitutive norm for belief is not one related to truth, but rather to the particular role that beliefs play in a 
subject's mental economy (Nolfi 2015, 197). Unlike my view, her actionoriented function of belief is taken to be essential to it, and out of that falls the evidential constraint on epistemic reasons (Nolfi 2018, 188). The relationship between Nolfi's framework and what she calls straightforward pragmatism is not uncomplicated, but one of her examples helps illustrate the difference:

Bella knows that she can secure substantial benefit or avoid substantial harm merely by believing that 2343 is a prime number, a false proposition, and one in support of which Bella has absolutely no evidence. Bella's future actions will be significantly more successful if she believes that 2343 is prime than if she fails to so believe. (Nolfi 2021, 11305)

As Nolfi notes, a straightforward pragmatist would say of this case that Bella ought to form the belief in question, given its practical advantages, and her doing so would not warrant negative epistemic evaluation. On Nolfi's action-oriented epistemology though, while we can recognize that the belief in question would facilitate successful action for Bella, we can also recognize that negative epistemic evaluation would be appropriate since the belief's action-related benefits do not survive contextual variation, and so the belief is not well-suited to fulfill the action-enabling function constitutive of belief (Nolfi 2021, 11305). The epistemic criticism that would be appropriate here comes from the nature of the pattern of belief-regulation responsible for the formation of Bella's belief - such a pattern would normally, as Nolfi puts it, "have gotten her into trouble" (Nolfi 2021, 11306). Similar things might be said about Dular and Fortier's own example of Jungkook, someone whose wrist will heal more quickly if they were to believe that it would heal faster than studies have shown (Dular and Fortier 2021, 1470). Dular and Fortier take it that in this case, despite the evidence suggesting Jungkook's wrist won't heal in fewer than three months "Jungkook should believe that they will heal in less than three months" $(2021,1470)$. But whether this intuition is shared will depend on the background notion of belief in play. De-prioritizing the role for truth or evidence in belief by making the relationship a contingent feature of evolutionary pressures doesn't automatically generate verdicts in favour of pragmatism.

So we see that breaking the constitutive link between belief on the one hand and truth or evidence on the other does not straightforwardly pave a way to pragmatism. What also matters is the essential nature of belief which forms part of the account. My explanation of transparency is silent on the nature of reasons for belief, but Nolfi's account which also does away with a constitutive belief-truth link is explicitly not pragmatism- 
friendly. Her conception of belief is thicker than my own, identifying it as an attitude that is meant to play a particular role in a believer's mental economy (Nolfi 2015, 197), and of course there are better and worse ways for something to play a role.

Dular and Fortier are explicitly silent on the essential nature of belief (2021, 1457, fn. 8). Whether their overall approach might be harnessed in a rebalancing of the prospects of pragmatism in the light of transparency will in part depend on what they take the essential nature of belief to be.

\section{Conclusions}

In defending pragmatism from the prima facie problem of transparency, Dular and Fortier turn to evolutionary debunking to explain this phenomenon as an evolutionary fix not properly sensitive to the truth about reasons to believe. I argued that taken one way-as a claim about our mechanisms for belief formation simpliciter-Dular and Fortier's explanation took a whole host of our beliefs outside of the scope of an evolutionary account, unless they have it that such cases are malfunctions. I argued that that would not be wise. I suggested that their dismissal of the plausibility of disjunctive evolutionary systems was too quick, and so they owe an explanation of why our practices of belief formation do not reflect pragmatism. On the other hand, if Dular and Fortier are happy to have nonevidential mechanisms as part of the story too, then the quick explanation they give of transparency (as being evolution's fix for adaptive belief formation), offers no more than is offered elsewhere (in a paper they say they diverge from the aims of). Overall then, either the cost of debunking transparency results in an implausible role for truth in fixing our beliefs across contexts, in which case the alternative explanation offered is not one we should want. Or we have merely the restatement of a view explicitly disavowed by the authors, in which case we have no alternative explanation after all. Finally, I argued that to be consistent with pragmatism, it matters what background theory of belief informs the explanation given of transparency. In particular, whether the harnessing of evolutionary considerations to soften the link between beliefs on the one hand and truth and evidence on the other is consistent with pragmatism will depend in part on taking a wider view of the essential nature of belief, a view not taken by Dular and Fortier. 


\section{Acknowledgments}

With thanks to the Arts and Humanities Research Council for funding the research of which this paper is a part (Deluded by Experience, grant no. $\mathrm{AH} / \mathrm{T} 013486 / 1)$. I am also grateful to two reviewers for this journal for helpful comments which improved the paper.

\section{REFERENCES}

Abelson, R. P. 1963. "Computer Simulation of Hot Cognition". In Computer Simulation of Personality, edited by Silvan S. Tomkins and Samuel Messick, 277-298. New York: Wiley.

Archer, Sophie. 2017. "Defending Exclusivity". Philosophy and Phenomenological Research 94 (2): 326-341. https://doi.org/10.1111/phpr.12268

Bayne, Tim, and Elisabeth Pacherie. 2005. "In Defence of the Doxastic Conception of Delusion". Mind \& Language 20 (2): 163-188. https://doi.org/10.1111/j.0268-1064.2005.00281.x

Bortolotti, Lisa. 2009. Delusions and Other Irrational Beliefs. Oxford: Oxford University Press.

Bykvist, Krister, and Anandi Hattiangadi. 2007. "Does Thought Imply Ought?" Analysis 67 (4): 277-285. https://doi.org/10.1093/analys/67.4.277

Dular, Nicole, and Nikki Fortier. 2021. "Epistemic Reasons, Transparency, and Evolutionary Debunking". Philosophia 49: 1455-1473. https://doi.org/10.1007/s11406-020-00302-6

Elster, Jon. 1983. Sour Grapes. New York: Cambridge University Press. Engel, Pascal 2007. "Belief and Normativity". Disputatio 2 (23): 179-204. https://doi.org/10.2478/disp-2007-0009.

Enoch, David. 2011. Taking Morality Seriously: A Defense of Robust Realism. New York: Oxford University Press.

Fineberg, Sarah K., and Philip R. Corlett. 2016. "The Doxastic Shear Pin: Delusions as Errors of Learning and Memory". Cognitive Neuropsychiatry 21 (1): 73-89.

https://doi.org/10.1080/13546805.2015.1136206

Fitzpatrick, William J. 2014. "Why There is No Darwinian Dilemma for Ethical Realism". In Challenges to Moral and Religious Belief:

Disagreement and Evolution, edited by Michael Bergmann and Patrick Kain, 237-255. New York: Oxford University Press.

Gold, Joel, and Ian Gold. 2014. Suspicious Minds: How Culture Shapes Madness. New York: Free Press. 
Hagen, Edward H. 2008. "Non-bizarre Delusions as Strategic Deception". In Medicine and Evolution, edited by Sarah Elton and Paul O'Higgins, 181-216. Boca Raton: CRC.

Joyce, Richard. 2001. The Myth of Morality. Cambridge: Cambridge University Press.

Lancellotta, Eugenia. 2021. "Is the Biological Adaptiveness of Delusions Doomed?" Review of Philosophy and Psychology. https://doi.org/10.1007/s13164-021000545-6

Lancellotta, Eugenia, and Lisa Bortolotti. 2020. "Delusions in the TwoFactor Theory: Pathological or Adaptive?" European Journal of Analytic Philosophy 16 (2): 37-57.

https://doi.org/10.31820/ejap.16.2.2

McCormick, Miriam Schliefer. 2015. Believing Against the Evidence: Agency and the Ethics of Belief. Abingdon: Routledge.

McHugh, Conor. 2012. "Beliefs and Aims". Philosophical Studies 160 (3): 425-439. https://doi.org/10.1007/s11098-011-9728-z

. 2013. "The Illusion of Exclusivity". European Journal of Philosophy 23 (4): 1117-1136. https://doi.org/10.1111/ejop.12032

McKay, Ryan, and Daniel Dennett. 2009. "The Evolution of Misbelief". Behavioral and Brain Sciences 32: 493-561. https://doi.org/ 10.1017/S0140525X09990975

Mele, Alfred R. 1997. "Real Self-deception". Behavioral and Brain Sciences 20: 91-136.

https://doi.org/10.1017/S0140525X97000034

2006. "Self-deception and Delusion". European Journal of Analytic Philosophy 2(1): 109-124.

Mishara, Aaron L., and Philip R. Corlett. 2009. "Are Delusions Biologically Adaptive? Salvaging the Doxastic Shear Pin". Behavioral and Brain Sciences 42 (6): 530-531. https://doi.org/10.1017/S0140525X09991464

O'Brien, Lucy. 2005. "Imagination and the Motivational Role of Belief". Analysis 65 (1): 55-62. https://doi.org/10.1093/analys/65.1.55

Nolfi, Kate. 2015. "How to be a Normativist about the Nature of Belief". Pacific Philosophical Quarterly 96: 181-204.

https://doi.org/10.1111/papq.12071

2018. "Why Only Evidential Considerations Can Justify Belief". In Normativity: Epistemic and Practical, edited by Conor McHugh, Jonathan Way, and Daniel Whiting, 179-199. Oxford: Oxford University Press.

—. 2021. "Epistemically Flawless False Beliefs". Synthese 198: 11291-11309. https://doi.org/10.1007/s11229-020-02787-w

Noordhof, Paul. 2003. "Self-Deception, Interpretation and Consciousness". Philosophy and Phenomenological Research 67 (1): 75-100. 
https://doi.org/10.1111/j.1933-1592.2003.tb00026.x

Owens, David J. 2003. "Does Belief Have an Aim?" Philosophical Studies

115 (3): 283-305. https://doi.org/10.1023/A:1025157101089

Quine, W. V. O. 1985. "Natural Kinds". In Naturalizing Epistemology, edited by Hilary Kornblith, 57-76. Cambridge, MA: MIT Press.

Ruse, Michael. 1986. "Evolutionary Ethics: A Phoenix Arisen”. Zygon 21

(1): 95-112. https://doi.org/10.1111/j.1467-

9744.1986.tb00736.x

Shah, Nishi. 2003. "How Truth Governs Belief". The Philosophical Review 112 (4): 447-482. https://doi.org/10.1215/00318108$112-4-447$

2006. “A New Argument for Evidentialism". The Philosophical Quarterly 56 (225): 481-98.

https://doi.org/10.1111/j.1467-9213.2006.454.x

Shah, Nishi and David J. Velleman. 2005. "Doxastic Deliberation". The

Philosophical Review 11 (4): 497-534.

https://doi.org/10.1215/00318108-114-4-497

Steglich-Petersen, Asbjørn. 2006. "No Norm Needed: On the Aim of

Belief”. The Philosophical Quarterly 56 (225): 499-516.

https://doi.org/10.1111/j.1467-9213.2006.455.x

2009. "Weighing the Aim of Belief". Philosophical Studies 145:

395-405.

https://doi.org/10.1007/s11098-008-9239-8

2017a. "Fictional Persuasion and the Aim of Belief". In Art and

Belief, edited by Ema Sullivan-Bissett, Helen Bradley, and Paul

Noordhof, 174-193. Oxford: Oxford University Press.

—. 2017b. "Weighing the Aim of Belief Again". Logos and Episteme

8 (1): 141-145.

https://doi.org/10.5840/logos-episteme2017819

Street, Sharon. 2009. "Evolution and the Normativity of Epistemic Reasons". Canadian Journal of Philosophy 39: 213-248. https://doi.org/10.1080/00455091.2009.10717649

Sullivan-Bissett, Ema. 2017a. “Aims and Exclusivity”. European Journal of Philosophy 25 (3): 721-731.

https://doi.org/10.1111/ejop.12183

2017b. "Transparency Defended". Symposium on Miriam McCormick's Believing Against the Evidence: Agency and the Ethics of Belief. Syndicate Philosophy.

- 2017c. "Biological Function and Epistemic Normativity". Philosophical Explorations 20 (1): 94-110. https://doi.org/10.1080/13869795.2017.1287296

2018. "Explaining Doxastic Transparency: Aim, Norm, or Function?" Synthese 195 (8): 3453-76.

https://doi.org/10.1007/s11229-017-1377-0 
2020. "We Are Like American Robins". In Epistemic Duties: New Arguments, New Angles, edited by Scott Stapleford and Kevin McCain, 954-110. Routledge.

Sullivan-Bissett, Ema, and Lisa Bortolotti. 2017. "Fictional Persuasion, Transparency, and the Aim of Belief". In Art and Belief, edited by Ema Sullivan-Bissett, Helen Bradley, and Paul Noordhof, 153-173. Oxford: Oxford University Press.

Sullivan-Bissett, Ema, and Paul Noordhof. 2013. "A Defence of Owens's Exclusivity Objection to Beliefs Having Aims". Philosophical Studies 163 (2): 453-457. https://doi.org/10.1007/s11098-0119824-0

2017. "Another Defence of Owens's Exclusivity Objection to Beliefs Having Aims". Logos and Episteme 8 (1): 147-153. https://doi.org/10.5840/logos-episteme20178110

— 2020. "The Transparent Failure of Norms to Keep Up Standards of Belief”. Philosophical Studies 177: 1213-1227.

https://doi.org/10.1007/s11098-019-01242-y

Talbott, W. J. 1995. "Intentional Self-Deception in a Single Coherent Self". Philosophy and Phenomenological Research 55 (1): 2774. https://doi.org/10.2307/2108309

Taylor, Shelley. E., and Jonathan D. Brown. 1994. "Positive Illusions and Well-being Revisited: Separating Fact from Fiction". Psychological Bulletin 116 (1): 21-27.

https://doi.org/10.1037/0033-2909.116.1.21

Trivers, Robert. 2000. "The Elements of a Scientific Theory of Selfdeception". Annals of the New York Academy of Sciences 907: 114-31. https://doi.org/10.1111/j.1749-6632.2000.tb06619.x 2011. Deceit and Self-deception: Fooling Yourself the Better to Fool Others. London: The Penguin Group.

2013. The Folly of Fools. The Logic of Deceit and Self-deception in Human Life. New York: Basic Books.

Van Leeuwen, Neil. 2007a. "The Spandrels of Self-Deception: Prospects for a Biological Theory of a Mental Phenomenon". Philosophical Psychology 20 (3): 329-48.

https://doi.org/10.1080/09515080701197148 2007b. "The Product of Self-Deception". Erkenntnis 67 (3): 419 437. https://doi.org/10.1007/s10670-007-9058-x 